Discussion Paper No. 918

\title{
EXCLUSIVE CONTRACTS WITH COMPLEMENTARY INPUTS
}

\author{
Hiroshi Kitamura \\ Noriaki Matsushima \\ Misato Sato
}

\begin{abstract}
January 2015
The Institute of Social and Economic Research Osaka University

6-1 Mihogaoka, Ibaraki, Osaka 567-0047, Japan
\end{abstract}




\title{
Exclusive Contracts with Complementary Inputs*
}

\author{
Hiroshi Kitamura $^{\dagger} \quad$ Noriaki Matsushima ${ }^{\ddagger}$ Misato Sato ${ }^{\S}$ \\ January 6, 2015
}

\begin{abstract}
This study constructs a model of anticompetitive exclusive contracts in the presence of complementary inputs. A downstream firm transforms multiple complementary inputs into final products. When complementary input suppliers have market power, upstream competition within a given input market benefits not only the downstream firm (by lowering the input price) but also complementary input suppliers (by raising complementary input prices). The downstream firm is thus unable to earn higher profits even when socially efficient entry is allowed. Hence, the inefficient incumbent supplier can deter socially efficient entry by using exclusive contracts even in the absence of economies of scale and downstream competition. These results have important implications for antitrust agencies, showing the importance of considering the existence of complementary inputs when examining cases of potential anticompetitive exclusive dealing.
\end{abstract}

JEL classifications code: L12, L41, L42.

Keywords: Antitrust policy; Complementary inputs; Exclusive dealing; Multiple inputs.

${ }^{*}$ We thank Eric Avenel, Chiara Fumagalli, Toshihiro Matsumura, Patrick Rey, Dan Sasaki, and Tetsuya Shinkai for their insightful comments. We also thank Akifumi Ishihara, Akihiko Nakagawa, Ryoko Oki, Noriyuki Yanagawa, the conference participants at EARIE 2014 (Bocconi University) and the Japanese Economic Association (Seinan Gakuin University), and the seminar participants at Kwansei Gakuin University, Kyoto University, Osaka University, The University of Rennes 1, and Yokohama National University for helpful discussions and comments. The second author thanks the warm hospitality at MOVE, Universitat Autònoma de Barcelona where part of this paper was written. We gratefully acknowledge financial support from JSPS Grant-in-Aid. The usual disclaimer applies.

${ }^{\dagger}$ Faculty of Economics, Kyoto Sangyo University, Motoyama, Kamigamo, Kita-Ku, Kyoto, Kyoto 603-8555, Japan. Email: hiroshikitamura@cc.kyoto-su.ac.jp

${ }^{\ddagger}$ Institute of Social and Economic Research, Osaka University, 6-1 Mihogaoka, Ibaraki, Osaka 567-0047, Japan. Email: nmatsush@iser.osaka-u.ac.jp

${ }^{\S}$ Department of Economics, The George Washington University, 2115 G street, NW Monroe Hall 340 Washington DC 20052, USA. Email: smisato@gwmail.gwu.edu 


\section{Introduction}

In vertical supply chain relationships, firms often engage in contracts including vertical restraints, such as exclusive contracts, loyalty rebates, slotting fees, resale price maintenance, quantity fixing, and tie-ins. ${ }^{1}$ Among vertical restraints, exclusive contracts have long been controversial. ${ }^{2}$ Once signed, exclusive contracts deter efficient entrants; they thus may appear to be anticompetitive. However, scholars from the Chicago School oppose this view by arguing, based on analytic models, that rational economic agents do not sign contracts to deter more efficient entrants (Posner, 1976; Bork, 1978). ${ }^{3}$ In rebuttals of this argument, postChicago economists indicate specific circumstances under which anticompetitive exclusive dealing occurs. ${ }^{4}$ These studies, by extending the single-buyer model upon which the Chicago School argument depends to a multiple-buyer model, introduce scale economies wherein the entrant requires a certain number of buyers to cover its fixed costs (Rasmusen, Ramseyer, and Wiley, 1991; Segal and Whinston, 2000a) and competition between buyers (Simpson and Wickelgren, 2007; Abito and Wright, 2008).

The present study extends this work by noting another economic environment within which anticompetitive exclusive dealing occurs: when there are complementary inputs. In a real-world business situation, final-good producers often transform multiple inputs into final products. More importantly, there exist complementary input suppliers with market power. In the Intel antitrust case, for example, Microsoft is a supplier with strong market power. ${ }^{5}$ Therefore, when applying analysis of anticompetitive exclusive dealing to real-world

\footnotetext{
${ }^{1}$ See, for example, Rey and Tirole (1986), Rey and Vergé (2010), and Asker and Bar-Issac (2014). See also Rey and Tirole (2007) and Rey and Vergé (2008) for surveys of vertical restraints.

${ }^{2}$ These exclusive-dealing agreements take various forms, such as restricting territories or rights. See, for instance, Mathewson and Winter (1984), Rey and Stiglitz (1995), and Matsumura (2003).

${ }^{3}$ For analysis of the impact of this argument on antitrust policies, see Motta (2004) and Whinston (2006).

${ }^{4}$ In an early contribution, Aghion and Bolton (1987) propose a model in which exclusion does not always occur, but, when it does, it is anticompetitive. See also Bernheim and Whinston (1998), which explores the market circumstances under which an exclusive contract can exclude rival incumbents.

${ }^{5}$ Intel was accused of awarding rebates and various other payments to major original equipment manufacturers (e.g., Dell and HP). In a single quarter in 2007, conditional rebates and payments from Intel amounted to 76\% of Dell's operating profit (Gans, 2013). See also Japan Fair Trade Commission (2005): http://www.jftc.go.jp/eacpf/cases/intel.pdf and the European Commission (2009):
} 
situations, the interaction between complementary input suppliers cannot be neglected.

In this study, we develop a model of anticompetitive exclusive dealing in the presence of complementary inputs. In our model, an upstream incumbent supplier offers an exclusive contract to a single downstream firm to deter an entrant supplier that is more efficient than the incumbent supplier-and would thus constitute a socially efficient entry. Because there are neither scale economies nor downstream competition, the incumbent supplier cannot deter socially efficient entry with exclusive contracts, as in the frameworks of previous studies. The new dimension in our model is that the downstream firm produces a final product using not only an input produced by the incumbent supplier but also a complementary input produced by a supplier with market power.

In a simple setting with linear demand and linear wholesale pricing, we first show that the existence of a complementary input supplier with market power allows the incumbent supplier to deter socially efficient entry via exclusive contracts, even in the case of a single downstream firm. To intuitively understand this result, consider the effects of socially efficient entry. Socially efficient entry into an input market generates competition, which reduces the input's price and thus allows the downstream firm to earn higher profits. Under the Chicago School argument, this effect prevents the incumbent supplier from profitably compensating the downstream firm; Chicago School scholars thus conclude that exclusion is impossible. However, when there is a complementary input supplier with market power, socially efficient entry into one input market increases the demand for the complementary input, which benefits the complementary input supplier by increasing the complementary input price. Hence, compared with the case in which there is no complementary input supplier with market power, socially efficient entry leads to a smaller increase in the downstream firm's profits. This allows the incumbent supplier to profitably compensate the downstream firm, and therefore exclusion is possible.

We also check the robustness of the above exclusion outcome and show that it can be observed in more general settings. First, introducing non-linear demand, we show that the http://ec.europa.eu/competition/sectors/ICT/intel.html. 
exclusion outcome results as long as the demand curve for final products is not overly convex; that is, exclusion is more likely to be observed under inelastic demand. Furthermore, a unique exclusion equilibrium occurs in a context of non-linear wholesale pricing and a general demand function. Therefore, the exclusion outcome identified in this study can be widely applied to diverse real-world vertical relationships.

This study is related to the literature on anticompetitive exclusive contracts (Rasmusen, Ramseyer, and Wiley, 1991; Segal and Whinston, 2000a; Simpson and Wickelgren, 2007; Abito and Wright, 2008). ${ }^{6}$ These studies share a common feature: reaching the exclusion result requires multiple downstream buyers. ${ }^{78}$ In contrast, this study shows that anticompetitive exclusive contracts can be signed even under a single-buyer model.

In terms of a single-buyer model of anticompetitive exclusive contracts, this study is closest to Fumagalli, Motta, and Rønde (2012) who explore a model in which exclusive dealing can both promote relationship-specific investment and foreclose a more efficient supplier. They show that if relationship-specific investment is possible, inefficient market foreclosure occurs even in the single-buyer model because the investment promotion effect of exclusive dealing increases the joint surplus of the incumbent seller and the downstream buyer under exclusive dealing. In contrast, exclusion in the present study arises because the existence of complementary inputs decreases the downstream firm's profits when socially efficient entry

\footnotetext{
${ }^{6}$ In addition, certain studies examine pro-competitive exclusive dealings; e.g., non-contractible investments (Marvel, 1982; Besanko and Perry, 1993; Segal and Whinston, 2000b; de Meza and Selvaggi, 2007; de Fontenay, Gans, and Groves, 2010), industry R\&D and welfare (Chen and Sappington, 2011), risk sharing (Argenton and Willems, 2012), and adverse selection (Calzolari and Denicolò, 2013). Exclusive dealing is also considered as a way to solve the commitment problem posited by Hart and Tirole (1990), which arises when a single upstream firm sells to multiple retailers with two-part tariffs under unobservable contracts. See also O'Brien and Shaffer (1992), McAfee and Schwartz (1994), and Rey and Vergé (2004).

${ }^{7}$ In the literature on exclusion with downstream competition, Fumagalli and Motta (2006) show that the existence of participation fees to remain active in the downstream market plays a crucial role in exclusion if buyers are undifferentiated Bertrand competitors. See also Wright's (2009) study, which corrects the result of Fumagalli and Motta (2006) in the case of two-part tariffs.

${ }^{8}$ For extended models of exclusion with downstream competition, see Wright (2008), Argenton (2010), and Kitamura $(2010,2011)$. Whereas these studies all show that the resulting exclusive contracts are anticompetitive, Gratz and Reisinger (2013) show potentially pro-competitive effects if downstream firms compete imperfectly and contract breaches are possible. See also DeGraba (2013) who adapts the model to cover a situation in which a small rival that is more efficient at serving a portion of the market can make exclusive offers.
} 
occurs.

This study is also related to the literature on vertical relationships involving complementary inputs, such as the work of Laussel (2008), Matsushima and Mizuno (2012, 2013), and Reisinger and Tarantino (2013). ${ }^{9}$ These studies demonstrate that vertical integration is not necessarily profitable because the complementary input supplier extracts the majority of the profits generated as a result of eliminating double marginalization through vertical integration. The present study extends this work, showing that these ideas can be applied to the literature on entry deterrence via exclusive contracts.

The remainder of this paper is organized as follows. Section 2 constructs the basic model. Section 3 presents the main results under linear wholesale pricing and extends the basic model in several dimensions. Section 4 provides analysis under non-linear wholesale pricing, while Section 5 offers concluding remarks. Additionally, the appendices support the work with proofs.

\section{Model}

This section develops the basic model environment. We first explain the basic characteristics of players and the game's timing in Section 2.1. Section 2.2 then introduces the design of the anticompetitive exclusive contracts.

\subsection{Basic environment}

The upstream market is composed of two complementary input markets: $A$ and $B$ (Figure 1). Input $A$ is exclusively produced by supplier $U_{A}$ with a constant marginal cost $c>0$. In contrast, input $B$ is produced by an incumbent supplier $U_{I B}$ and an entrant supplier $U_{E B}$. Following the Chicago School model, $U_{I B}$ and $U_{E B}$ produce an identical product but with differing cost efficiencies; namely, $U_{E B}$ is more efficient than $U_{I B}$, with a constant marginal cost $c_{E} \in[0, c)$ as opposed to $U_{I B}$ 's constant marginal cost $c>0$.

\footnotetext{
${ }^{9}$ See also Arya and Mittendorf (2007) and Laussel and Long (2012).
} 
The downstream market is composed of a single firm. This modeling strategy clarifies the role of $U_{A}$ as having market power; that is, the prevention of socially efficient entry occurs even in the absence of scale economies and downstream competition, both of which require more than one downstream firm. A downstream monopolist $D$ transforms inputs $A$ and $B$ into a final product. $D$ uses Leontief production technology: one unit of the final product is made with one unit of input $A$ and one unit of input $B:^{10}$

$$
Q=\min \left\{q_{A}, q_{B}\right\},
$$

where $q_{i}$ is the amount of input $i \in\{A, B\}$. Equation (1) implies that the two inputs are essential to produce a final product in a downstream market-i.e., they are perfect complements. ${ }^{11}$ The payment for $q_{i}$ units of input $i \in\{A, B\}$ is given as $w_{i} q_{i}$, where $w_{i}$ is input $i$ 's price. To simplify the analysis, we assume that $D$ incurs no production costs aside from paying for the two inputs. Thus, per unit production cost of $D$ is given by

$$
c_{D}=w_{A}+w_{B} .
$$

We assume that the inverse demand for the final product $P(Q)$ is given by a simple linear function:

$$
P(Q)=a-b Q,
$$

where $Q$ is the output of the final product supplied by $D, a>2\left(2 c-c_{E}\right)$, and $b>0$. The first inequality implies that $U_{E B}$ 's monopoly price is higher than $c$; namely, the existence of $U_{I B}$ always acts a constraint on the pricing of $U_{E B}$ when $U_{E B}$ enters the market for input $B .^{12}$

The model contains four stages (Figure 2). In Stage 1, $U_{I B}$ makes an exclusive offer to $D$ with fixed compensation $x \geq 0$. D decides whether to accept the offer. ${ }^{13} D$ immediately

\footnotetext{
${ }^{10}$ Introducing asymmetric production technology where one unit of the final product is made with $h>0$ units of input $A$ and $m>0$ units of input $B$ does not qualitatively change the results.

${ }^{11}$ Such production technology can be widely observed in real-world manufacturing. For example, producing a PC requires a CPU and an operating system, and producing a car requires a body and tires.

${ }^{12}$ Exclusion will still exist even when $U_{E B}$ is more efficient, but the analysis becomes more complicated. In Section 4, we consider a case in which the demand function follows a general demand form.

${ }^{13}$ Rasmusen, Ramseyer, and Wiley (1991) and Segal and Whinston (2000a) point out that price commitments
} 
receives $x$ if it accepts the offer. In Stage 2, $U_{E B}$ decides whether to enter the market for input $B$. We assume that the fixed entry cost is sufficiently small that $U_{E B}$ can earn positive profits. In Stage 3, active suppliers offer linear input prices to $D$. (In Section 4, we introduce non-linear pricing.) We assume that if $U_{E B}$ enters the market for input $B$, then $U_{I B}$ and $U_{E B}$ become homogeneous Bertrand competitors. The equilibrium price of input $i \in\{A, B\}$ when $D$ accepts (rejects) the exclusive offer is denoted by $w_{i}^{a}\left(w_{i}^{r}\right)$ where the superscript ' $a$ ' (' $r$ ') indicates that the exclusive offer is accepted (rejected). In Stage 4, D orders inputs and sells the final product to consumers. $U_{k}$ 's profit in the case where $D$ accepts (rejects) the exclusive offer is denoted by $\pi_{k}^{a}\left(\pi_{k}^{r}\right)$, where $k \in\{A, I B, E B\}$. D's profit in the case when it accepts (rejects) the exclusive offer is denoted by $\pi_{D}^{a}\left(\pi_{D}^{r}\right)$.

\subsection{Design of exclusive contracts}

For an exclusion equilibrium to exist, the equilibrium transfer $x^{*}$ must satisfy the following two conditions.

First, it must satisfy individual rationality for $U_{I B}$; that is, $U_{I B}$ earns higher profits under exclusive dealing:

$$
\pi_{I B}^{a}-x^{*} \geq \pi_{I B}^{r}
$$

Second, the exclusive contract must satisfy individual rationality for $D$; that is, the amount of compensation $x$ induces $D$ to accept the exclusive offer:

$$
\pi_{D}^{a}+x^{*} \geq \pi_{D}^{r}
$$

From the above conditions, it is evident that a unique exclusion equilibrium exists if and only if inequalities (3) and (4) simultaneously hold. This is equivalent to the following condition:

$$
\pi_{I B}^{a}+\pi_{D}^{a} \geq \pi_{I B}^{r}+\pi_{D}^{r}
$$

are unlikely if the product's nature is not described precisely in advance. In the naked exclusion literature, it is known that if the incumbent can commit to wholesale prices, then anticompetitive exclusive dealings are enhanced. See Yong (1999) and Appendix B of Fumagalli and Motta (2006). 
Condition (5) implies that to determine whether anticompetitive exclusive contracts exist, we must examine whether exclusive contracts increase the joint profits of $U_{I B}$ and $D$.

\section{Linear wholesale pricing}

This section analyzes the existence of anticompetitive exclusive contracts under linear wholesale pricing. To intuitively understand the importance of a complementary input supplier having market power, we first discuss a benchmark case in which complementary input $A$ is competitively provided (Section 3.1). We then explore the case in which complementary input $A$ is supplied by a monopolistic supplier and also examine how the curvature of the inverse demand function influences the result (Section 3.2). Finally, Section 3.3 discusses how market power in input market $A$ influences the result in Section 3.2.

\subsection{Benchmark: When a complementary input is competitively sup- plied}

Assume that complementary input $A$ is competitively provided. Then, input $A$ 's price does not depend on whether the exclusive offer is accepted in Stage 1; i.e., $w_{A}^{a}=w_{A}^{r}=c$. In this setting, the Chicago School model can be interpreted as a special case in which $D$ can purchase complementary input $A$ for free; i.e., $w_{A}^{a}=w_{A}^{r}=0 .{ }^{14}$ Therefore, as the Chicago School approach argues, $U_{I B}$ cannot deter socially efficient entry.

Proposition 1. Suppose that inverse demand is given by a linear function and upstream suppliers adopt linear wholesale pricing. When complementary input A is competitively provided, $U_{I B}$ cannot deter socially efficient entry by using exclusive contracts.

The result here can be explained using logic similar to that underlying the Chicago School argument. When $D$ accepts the exclusive offer in Stage 1, it purchases input $B$ from $U_{I B}$

\footnotetext{
${ }^{14}$ Although a buyer is the final consumer in the Chicago School model, the result does not qualitatively change if we assume that the buyer is a downstream monopolist. See Lemma 1 of Kitamura, Sato, and Arai (2014).
} 
at a higher input price, which allows $U_{I B}$ to earn monopoly profits. However, under linear wholesale pricing, $U_{I B}$ and $D$ cannot maximize their joint profits because of the double marginalization problem. Thus, the left-hand side of inequality (5) is quite small.

In contrast, when $D$ rejects the exclusive offer in Stage $1, U_{E B}$ enters the market for input $B$ in Stage 2. In Stage 3, $U_{I B}$ and $U_{E B}$ compete to manage $D$. Compared with the case of exclusive dealing, upstream competition in the $B$ market reduces input $B$ 's price, which solves the double marginalization problem. Thus, $D$ earns considerably higher rejection profits; that is, the right-hand side of inequality (5) becomes large. In the absence of scale economies and downstream competition, $U_{I B}$ cannot profitably compensate $D$, implying that there is no $x$ that simultaneously satisfies participation constraints (3) and (4). Therefore, when the downstream market consists of a monopolist, anticompetitive exclusive dealing cannot occur if complementary input $A$ is competitively supplied.

\subsection{When a complementary input is provided by a monopolist}

We now assume that complementary input $A$ is provided exclusively by $U_{A}$. Input $A$ 's price now depends on whether entry into the market for input $B$ occurs, unlike in the previous subsection. As in the case where complementary input $A$ is provided competitively, entry into the market for input $B$ generates competition within it, reducing $B$ 's price. To understand the pricing behavior of $U_{A}$ when input $B$ 's price decreases, we first examine the relationship between entry into the $B$ market and input $A$ 's price. The following lemma summarizes the relationship:

Lemma 1. When $U_{A}$ has market power, socially efficient entry into the market for input B raises the equilibrium price of input $A$-that is, $w_{A}^{r}>w_{A}^{a}$.

To understand this result, consider the reaction function of the monopolistic supplier of input $i$ given input $j$ 's price $w_{j}$;

$$
w_{i}\left(w_{j}\right)=\frac{a+c-w_{j}}{2 b}
$$


where $i, j \in\{A, B\}$ and $i \neq j$. It is easy to see that the strategic interaction between the two monopolistic suppliers is strategic substitute; that is, raising input $A$ 's price is the best response for $U_{A}$ when input $B$ 's price decreases. ${ }^{15}$ Therefore, entry into the market for input $B$ induces $U_{A}$ to raise input $A$ 's price and enjoy higher profits. The following proposition shows that this relationship between entry into the market for input $B$ and input $A$ 's price allows $U_{I B}$ to deter efficient entry by using exclusive contracts:

Proposition 2. Suppose that inverse demand is given by a linear function and upstream suppliers adopt linear wholesale pricing. If $U_{A}$ is the monopolist for input $A, U_{I B}$ can deter socially efficient entry as a unique exclusionary equilibrium outcome.

Note that the crucial difference as compared to the benchmark case exists in the subgame in which $D$ rejects the exclusive offer. As in the case in which input $A$ is competitively supplied, entry into the market for input $B$ generates upstream competition in this market, which benefits $D$. However, Lemma 1 implies that entry into this market also benefits $U_{A}$ by increasing input $A$ 's price, which prevents $D$ from earning considerably higher profits upon rejecting the exclusive offer; that is, the right-hand side of inequality (5) does not become sufficiently large. This allows $U_{I B}$ to profitably compensate $D$ using its profits under exclusive dealing. Therefore, the existence of a complementary supplier with market power leads to anticompetitive exclusive dealing even in the absence of scale economies and downstream competition.

Remark (Non-linear demand) The previous results rest on the assumption of a linear inverse demand function. We now relax this assumption to extend Section 3.2's analysis with a non-linear inverse demand function:

$$
P(Q)=a-b Q^{\alpha}
$$

\footnotetext{
${ }^{15}$ If inputs $A$ and $B$ were substitutes, a reduction in input $B$ 's price would decrease demand for input $A$, and thus $U_{A}$ would be required to lower $A$ 's price. In contrast, if inputs $A$ and $B$ are complements, a reduction in input $B$ 's price increases demand for input $A$.
} 
We assume that $\alpha>0$ so that firms' second-order conditions are satisfied. We also assume that $a>\left((1+\alpha)\left(c-c_{E}\right)+2 \alpha c\right) / \alpha$ so that $U_{E B}$ 's monopoly price is higher than $c$. Comparing equations (2) and (6) reveals clearly that the linear demand case considered in the previous subsections is a special case in which $\alpha=1$. The price elasticity of demand is given by

$$
-\frac{d Q / Q}{d p / p}=\frac{p}{\alpha(a-p)}
$$

Equations (6) and (7) imply that as $\alpha$ increases (decreases), the demand curve becomes concave (convex) or inelastic (elastic). The following proposition shows that the likelihood of exclusion depends on the curve's shape.

Proposition 3. Suppose that upstream suppliers adopt linear wholesale pricing. If $U_{A}$ is the monopolistic supplier of input $A, U_{I B}$ can deter socially efficient entry as a unique equilibrium outcome as long as the demand curve for the final product is not overly convex, $\alpha \geq \bar{\alpha} \simeq$ 0.40692 .

This result has an important implication: exclusion is more likely to be observed when demand is inelastic. The curvature of the inverse demand curve influences the degree of demand-expansion following socially efficient entry. When the inverse demand curve is concave $(\alpha>1)$, the demand-expansion effect of a new upstream entrant is weak; as a result, socially efficient entry does not lead to a large increase in $D$ 's profits, allowing $U_{I B}$ to profitably compensate $D$. However, as the inverse demand curve becomes convex, the demandexpansion effect becomes significant; in other words, the double marginalization problem is more serious in the case of convex inverse demand. This leads to a large increase in $D$ 's profits, preventing $U_{I B}$ from profitably compensating $D$.

\subsection{Discussion}

To probe how the monopoly power of a complementary input supplier influences the previous subsection's outcome, we briefly discuss the case in which a competitor also supplies complementary input $A$. We suppose that input $A$ is produced by not only an incumbent supplier, 
$U_{I A}$, but also an inefficient supplier, $U_{E A}$. The marginal cost of $U_{E A}$ is $d_{A} \in(c, a / 2)$. We assume that $U_{E A}$ enters the market for input $A$ in Stage 2, that $U_{I A}$ and $U_{E A}$ are homogeneous Bertrand competitors, and that the fixed cost of entry is zero, enabling $U_{E A}$ to enter the market for input $A .^{16}$ Note that the analyses in Section 3.1 and 3.2 can be interpreted as the cases in which $d_{A}=c$ and $d_{A} \geq a / 2$, respectively. The following proposition shows that the likelihood of exclusion depends on the difference in efficiency between the suppliers of complementary input $A .^{17}$

Proposition 4. Suppose that input A can be produced by $U_{I A}$ and $U_{E A}$. $U_{I B}$ can deter socially efficient entry as a unique equilibrium outcome if the efficiency difference between the suppliers of complementary input $A$ is sufficiently large-that is, $d_{A} \geq \bar{d}_{A}$ where

$$
\bar{d}_{A}=a-c-\frac{a-2 c}{\sqrt{3}} .
$$

Note that $c<\bar{d}_{A}<a / 2$. The result here fills the gap between Propositions 1 and 2 and confirms the significance of the complementary input supplier being able to control its input price. When $U_{E A}$ 's efficiency is high (that is, $d_{A}$ is close to $c$ ), the existence of $U_{E A}$ acts as a constraint on the pricing of $U_{I A}$ and significantly dampens the monopoly power of $U_{I A}$. This implies that $U_{I A}$ does not extract sufficient profits from $D$, regardless of whether $U_{I B}$ 's exclusive offer is accepted. In this environment, engaging in exclusive dealing with $U_{I B}$ significantly reduces $D$ 's profit through double marginalization.

In contrast, when $U_{E A}$ is sufficiently inefficient (that is, $\left.d_{A} \in((a+c) / 3, a / 2)\right)$, the existence of $U_{E A}$ does not necessarily constrain the pricing of $U_{I A}$. On the one hand, if $U_{I B}$ 's exclusive offer is accepted, the existence of $U_{E A}$ never influences $U_{I A}$ 's pricing decisions. On the other, if $U_{I B}$ 's exclusive offer is rejected, the existence of $U_{E A}$ does constrain $U_{I A}$ 's pricing decisions. In this case, input $A$ 's price depends on $U_{E A}$ 's efficiency, $d_{A}$. As noted in Section 3.2,

\footnotetext{
${ }^{16}$ If the entry cost is positive, $U_{E A}$ does not enter input $A$ market because it anticipates zero operating profits and cannot cover this fixed cost. It may be harder to justify this assumption. However, even if $U_{E A}$ had to incur the fixed cost, it might enter. For example, this might occur if there were upstream differentiation in input $A$ 's market. Alternatively, if $U_{E A}$ is already established and operating in other industries, it could supply input $A$ without additional fixed costs.

${ }^{17}$ The result does not change even though we assume that both $U_{I A}$ and $U_{I B}$ independently and simultaneously make exclusive offers to $D$ with fixed compensation $x_{A}(\geq 0)$ and $x_{B}(\geq 0)$, respectively.
} 
the stronger the monopoly power of $U_{I A}$, the lower $D$ 's profitability if $U_{I B}$ 's exclusive offer is

rejected. Therefore, if $U_{E A}$ 's efficiency is low enough that $d_{A} \geq \bar{d}_{A}$, then $U_{I B}$ and $D$ engage in anticompetitive exclusive dealing even in the presence of competition in the complementary input market.

Interpretation of these results yields an important policy implication for antitrust agencies: an increase in the cost efficiency of a dominant input supplier can facilitate anticompetitive exclusive dealing in complementary input markets. As the dominant input supplier becomes more efficient, industry output usually increases, which is socially efficient. However, if we consider the possibility of exclusive contracts in complementary input markets, an improvement in the efficiency of the dominant input supplier may trigger exclusion outcomes in complementary input markets, which is socially inefficient. Therefore, when considering real-world exclusive contracts, antitrust agencies should pay attention to not only the structure of the market in which the exclusive contracts are signed but also structural changes in related complementary input markets.

\section{Non-linear wholesale pricing}

In this section, we extend Section 3.2's model analysis to the case in which upstream suppliers use two-part tariffs in Stage 3. Two-part tariffs consist of a linear wholesale price and an upfront fixed fee; the two-part tariff offered by input supplier $i \in\{A, I B, E B\}$ when $D$ accepts (rejects) the exclusive offer is denoted by $\left(w_{i}^{a}, F_{i}^{a}\right)\left(\left(w_{i}^{r}, F_{i}^{r}\right)\right)$. Under non-linear pricing, the double marginalization problem is avoidable, and the joint profit is maximized within the technological endowments available to firms. For notational convenience, we define $\Pi^{*}(z)$ as follows:

$$
\Pi^{*}(z) \equiv \max _{p}(p-z-c) Q(p),
$$

where $z \geq 0$ and $Q(p)$ is a general demand function. $\Pi^{*}(z)$ can be interpreted as the maximum joint profit when input $B$ is supplied with marginal cost $z$. When entry does not occur (occurs), we have $z=c\left(z=c_{E}\right)$. Hence, the difference between $\Pi^{*}\left(c_{E}\right)$ and $\Pi^{*}(c)$ depends on the 
difference between the efficiencies of $U_{E B}$ and $U_{I B}$. To simplify the analysis, we assume that $\Pi^{*}(z)$ is continuous and strictly decreasing in $z$.

We first consider the case in which the exclusive offer is accepted in Stage 1. There are multiple equilibria in which $U_{A}$ and $U_{I B}$ respectively offer $\left(c, F_{A}^{a}\right)$ and $\left(c, F_{I B}^{a}\right)$ such that $F_{A}^{a}+F_{I B}^{a}=\Pi^{*}(c)$. The firms' equilibrium profits, excluding the fixed compensation $x$, are

$$
0 \leq \pi_{A}^{a} \leq \Pi^{*}(c), \quad 0 \leq \pi_{I B}^{a} \leq \Pi^{*}(c), \pi_{D}^{a}=0
$$

where $\pi_{A}^{a}+\pi_{I B}^{a}=\Pi^{*}(c)$. Multiple equilibria consist of any $F_{A}^{a} \geq 0$ and $F_{I B}^{a} \geq 0$ such that $F_{A}^{a}+F_{I B}^{a}=\Pi^{*}(c)$.

We next consider the case in which the exclusive offer is rejected in Stage 1. In Stage 2, $U_{E B}$ then enters the market for input $B$. In Stage 3, $U_{I B}$ offers its best term $(c, 0)$. Anticipating this term, $U_{A}$ and $U_{E B}$ respectively offer $\left(c, F_{A}^{r}\right)$ and $\left(c_{E}, F_{E B}^{r}\right)$, which satisfy $\Pi^{*}\left(c_{E}\right)-F_{E B}^{r}-$ $F_{A}^{r} \geq \Pi^{*}(c)-F_{A}^{r}$ if $F_{A}^{r} \leq \Pi^{*}(c)$ and $\Pi^{*}\left(c_{E}\right)-F_{E B}^{r}-F_{A}^{r} \geq 0$ if $F_{A}^{r}>\Pi^{*}(c)$. The inequalities that include $F_{E B}^{r}$ indicate that $D$ either prefers $U_{E B}$ 's offer to that of $U_{I B}$ or treats them equally. By arranging the condition, we conclude that $\left(c, F_{A}^{r}\right)$ and $\left(c_{E}, F_{E B}^{r}\right)$ satisfy the following: $0 \leq F_{E B}^{r} \leq \Pi^{*}\left(c_{E}\right)-\Pi^{*}(c)$ and $F_{A}^{r}+F_{E B}^{r}=\Pi^{*}\left(c_{E}\right)$. Equilibrium firms' profits are then given as follows:

$$
\Pi^{*}(c) \leq \pi_{A}^{r} \leq \Pi^{*}\left(c_{E}\right), \quad \pi_{I B}^{r}=\pi_{D}^{r}=0, \quad 0 \leq \pi_{E B}^{r} \leq \Pi^{*}\left(c_{E}\right)-\Pi^{*}(c),
$$

where $\pi_{A}^{r}+\pi_{E B}^{r}=\Pi^{*}\left(c_{E}\right)$. Multiple equilibria consist of any $\Pi^{*}(c) \leq F_{A}^{r} \leq \Pi^{*}\left(c_{E}\right)$ and $0 \leq F_{E B}^{r} \leq \Pi^{*}\left(c_{E}\right)-\Pi^{*}(c)$ such that $F_{A}^{r}+F_{E B}^{r}=\Pi^{*}\left(c_{E}\right)$.

Finally, we check for the existence of exclusion. Because we have $\pi_{I B}^{a}+\pi_{D}^{a}-\left(\pi_{I B}^{r}+\pi_{D}^{r}\right) \geq 0$ with equality for $\pi_{I B}^{a}=0$, inequality (5) always holds. Therefore, exclusion is always an equilibrium outcome.

Proposition 5. Suppose that upstream suppliers adopt two-part tariffs. If $U_{A}$ has market power, then $U_{I B}$ can deter socially efficient entry as a unique equilibrium outcome.

There are a few remarks that must be made regarding this section's analysis. First, as pointed out above, there exist multiple equilibria in Stage 3. Second, the profit allocation is 
not consistent with the linear wholesale pricing case. When complementary input suppliers adopt two-part tariffs, $D$ earns zero operating profits regardless of its decision in Stage 1. Hence, the main intuition of the Chicago School argument, in which the downstream buyer enjoys a large surplus, cannot be applied.

\section{Concluding remarks}

This study explores the existence of anticompetitive exclusive dealing, extending the work of previous studies to consider the role of complementary inputs in the upstream market. It is essential that this interaction between complementary input suppliers not be neglected, as it is common for real-world downstream firms to transform multiple inputs into final products.

Our analysis shows that seemingly small differences in the model's setting can have crucial ramifications for the results. If the complementary input supplier has market power, then the inefficient incumbent supplier can deter socially efficient entry by using exclusive contracts even under the Chicago School argument's framework in which there is a single downstream buyer. On checking the robustness of our exclusion outcome, we show that it does not depend on the assumption of linear demand or linear wholesale pricing; that is, our results remain valid when the final product demand curve is not too convex or when nonlinear wholesale pricing is introduced. This study's analysis can thus be widely applied to real-world vertical relationships.

Our results also have novel and important implications for antitrust agencies: it is necessary to take into account the existence of complementary inputs when considering the possibility of anticompetitive exclusive dealing. If we discuss the anticompetitiveness of exclusive contracts while ignoring the existence of complementary input suppliers with market power, we might over-emphasize the results of the Chicago School argument. This study's results suggest that rational economic agents can easily engage in anticompetitive exclusive dealing in a market requiring multiple inputs to produce a downstream product for which demand is inelastic. 
Despite these contributions, there remain several outstanding issues requiring further research. The first involves this study's relationship to other studies of anticompetitive exclusive dealing. For example, we assume that the downstream firm is a monopolist. We predict that, as Simpson and Wickelgren (2007) and Abito and Wright (2008) discuss, adding downstream competition to our model would increase the likelihood of reaching an exclusion equilibrium. In addition, we assume a single entrant in each input market. As Kitamura (2010) discusses, the likelihood of an exclusion equilibrium decreases if multiple entrants are added to the model.

The second area for further analysis concerns the generality of our results. For example, the present study's analysis assumes Leontief production technology. While this might be appropriate for analyzing certain real-world situations, such as the Intel antitrust case, the result might also remain valid under more general production technologies. In addition, in Section 3.3 we assume that the complementary input suppliers are homogeneous Bertrand competitors. If we were to add differentiation between the complementary input suppliers to our model, the likelihood of an exclusion equilibrium would increase. A real-world example of this is the case of Eastman Kodak v. Fuji, in which Kodak complained of exclusive contracts between Fuji and Japanese wholesalers that prevented Kodak from successfully entering Japan's photographic film market. ${ }^{18}$ The Japanese camera market, which complements the film market, is characterized by dominant manufacturers such as Canon and Nikon. These manufacturers are somewhat differentiated and have market power because consumers face switching costs when considering changing cameras. Extensions and applications of our model can thus help researchers and policymakers address similar real-world issues.

\footnotetext{
${ }^{18}$ See, for example, Nagaoka and Goto (1997).
} 


\section{A Proofs of All Results}

\section{Proof of Proposition 1}

Before, we proceed the proof, we explain $D$ 's maximization problem. Given the input prices, $w_{A}$ and $w_{B}$, the problem is given as

$$
\max _{Q}\left(a-b Q-w_{A}-w_{B}\right) Q .
$$

The output of the final product supplied by $D$ and the demand for each input are

$$
q_{A}=q_{B}=Q\left(w_{A}, w_{B}\right) \equiv \frac{a-w_{A}-w_{B}}{2 b} .
$$

When input $A$ is competitively provided, we have $w_{A}^{a}=w_{A}^{r}=c$. We first explore the case where the exclusive contract is accepted in Stage 1. The outcome in Stage 4 is given in (9). In Stage 3, $U_{I B}$ sets the input price;

$$
w_{B}^{a}=\arg \max _{w_{B}}\left(w_{B}-c\right) Q\left(c, w_{B}\right) .
$$

The equilibrium input prices are $w_{B}^{a}=a / 2$ and $w_{A}^{a}=c$. From (9), the equilibrium production levels are $Q^{a}(c, a / 2)=q_{A}^{a}=q_{B}^{a}=(a-2 c) / 6 b$. The firms' equilibrium profits, excluding the fixed compensation $x$, are

$$
\pi_{A}^{a}=0, \quad \pi_{I B}^{a}=\frac{(a-2 c)^{2}}{8 b}, \Pi_{D}^{a}=\frac{(a-2 c)^{2}}{16 b} .
$$

We next explore the case where the exclusive offer is rejected in Stage 1. Then, $U_{E B}$ enters the $B$ market in Stage 2. In Stage 3, the competition in the $B$ market reduces input $B$ 's price to $U_{I B}$ 's marginal cost; i.e., $w_{B}^{r}=c$. From (9), the equilibrium production levels are $Q^{r}(c, c)=q_{A}^{r}=q_{B}^{r}=(a-2 c) / 2 b$. The equilibrium profits are

$$
\pi_{A}^{r}=\pi_{I B}^{r}=0, \pi_{D}^{r}=\frac{(a-2 c)^{2}}{4 b} .
$$

Finally, we check the existence of an exclusion equilibrium. From (10) and (11), we have

$$
\pi_{I B}^{a}+\pi_{D}^{a}-\left(\pi_{I B}^{r}+\pi_{D}^{r}\right)=-\frac{(a-2 c)^{2}}{16 b}<0
$$

which implies that condition (5) never holds.

Q.E.D. 


\section{Proof of Lemma 1}

Suppose first that the exclusive offer is accepted in Stage 1. The maximization problem of $D$ in Stage 4 is given as (8). The output of the final product supplied by $D$ and the demand for each input are given as (9). The maximization problem of supplier $i$ in Stage 3 is given as

$$
\max _{w_{i} \geq c}\left(w_{i}-c\right) Q\left(w_{i}, w_{j}\right),
$$

where $i, j \in\{A, B\}, i \neq j$. The first-order conditions lead to the equilibrium input prices:

$$
w_{A}^{a}=w_{B}^{a}=\frac{a+c}{3} .
$$

From (9), the equilibrium production levels are $Q^{a}=q_{A}^{a}=q_{B}^{a}=Q((a+c) / 3,(a+c) / 3)=$ $(a-2 c) / 6 b$. The firms' equilibrium profits, excluding the fixed compensation $x$, are

$$
\pi_{A}^{a}=\pi_{I B}^{a}=\frac{(a-2 c)^{2}}{18 b}, \pi_{D}^{a}=\frac{(a-2 c)^{2}}{36 b} .
$$

Suppose next that the exclusive offer is rejected in Stage 1. In this case, $U_{E B}$ enters the $B$ market in Stage 2. The maximization problem of $D$ in Stage 4 is given as (8). The output of the final product supplied by $D$ and the demand for each input are given as (9). The competition in the $B$ market in Stage 3 leads to $w_{B}^{r}=c$. By contrast, the maximization problem of $U_{A}$ in Stage 3 is given as (12). The equilibrium price of input $A$ is

$$
w_{A}^{r}=\frac{a}{2} .
$$

From (9), the equilibrium production levels are $Q^{r}=q_{A}^{r}=q_{B}^{r}=(a-2 c) / 4 b$. The equilibrium profits of firms are

$$
\pi_{A}^{r}=\frac{(a-2 c)^{2}}{8 b}, \pi_{I B}^{r}=0, \pi_{D}^{r}=\frac{(a-2 c)^{2}}{16 b} .
$$

From (13) and (15), we have the following relation:

$$
w_{A}^{a}-w_{A}^{r}=-\frac{a-2 c}{6}<0 .
$$

Therefore, entry into the $B$ market increases input $A$ 's price.

Q.E.D. 


\section{Proof of Proposition 2}

From (14) and (16), we have

$$
\pi_{I B}^{a}+\pi_{D}^{a}-\left(\pi_{I B}^{r}+\pi_{D}^{r}\right)=\frac{(a-2 c)^{2}}{48 b}>0
$$

which implies that condition (5) always holds.

Q.E.D.

\section{Proof of Proposition 3}

We first consider the case where the exclusive offer is accepted in Stage 1. The firms' equilibrium profits, excluding the fixed compensation $x$, are

$$
\pi_{I B}^{a}=\frac{\alpha}{((1+\alpha) b)^{\frac{1}{\alpha}}}\left(\frac{a-2 c}{1+2 \alpha}\right)^{\frac{1+\alpha}{\alpha}}, \pi_{D}^{a}=\frac{\alpha}{b^{\frac{1}{\alpha}}}\left(\frac{\alpha(a-2 c)}{(1+\alpha)(1+2 \alpha)}\right)^{\frac{1+\alpha}{\alpha}} .
$$

We next consider the case where the exclusive offer is rejected in Stage 1. The equilibrium profits of firms are given as

$$
\pi_{I B}^{r}=0, \quad \pi_{D}^{r}=\frac{\alpha}{b^{\frac{1}{\alpha}}}\left(\frac{a-2 c}{(1+\alpha)^{2}}\right)^{\frac{1+\alpha}{\alpha}} .
$$

Finally, we consider the existence of exclusion. By using above results, we have

$$
\pi_{I B}^{a}+\pi_{D}^{a}-\left(\pi_{I B}^{r}+\pi_{D}^{r}\right)=\frac{\alpha(a-2 c)^{\frac{1+\alpha}{\alpha}}}{b^{\frac{1}{\alpha}}} \frac{(1+\alpha)^{\frac{2(1+\alpha)}{\alpha}}(2+\alpha)-((1+\alpha)(1+2 \alpha))^{\frac{1+\alpha}{\alpha}}}{(1+\alpha)^{\frac{3(1+\alpha)}{\alpha}}(1+2 \alpha)^{\frac{1+\alpha}{\alpha}}} \geq 0,
$$

if and only if $\alpha \geq \bar{\alpha}$. Therefore, condition (5) holds if and only if $\bar{\alpha}<\alpha$.

Q.E.D.

\section{Proof of Proposition 4}

We first consider the case where $U_{I B}$ 's exclusive offer is accepted in Stage 1. The existence of $U_{E A}$ acts as a constraint on the pricing of $U_{I A}$ although $U_{I A}$ is the supplier of input $A$ on 
the equilibrium path. $U_{I B}$ monopolistically sets input $B$ 's price. The maximization problem of $D$ in Stage 4 is given as (8). The output of the final product supplied by $D$ and the demand for each input are (9). The maximization problems of $U_{I A}$ and $U_{I B}$ in Stage 3 are given as

$$
\begin{aligned}
& \max _{w_{A}}\left(w_{A}-c\right) \frac{a-w_{A}-w_{B}}{2 b}, \text { s.t. } w_{A} \leq d_{A}, \\
& \max _{w_{B}}\left(w_{B}-c\right) \frac{a-w_{A}-w_{B}}{2 b} .
\end{aligned}
$$

These maximization problems lead to

$$
w_{A}^{a}=\left\{\begin{array}{ll}
d_{A} & \text { if } c<d_{A}<\frac{a+c}{3}, \\
\frac{a+c}{3} & \text { if } d_{A} \geq \frac{a+c}{3},
\end{array} \quad w_{B}^{a}= \begin{cases}\frac{a+c-d_{A}}{2} & \text { if } c<d_{A}<\frac{a+c}{3}, \\
\frac{a+c}{3} & \text { if } d_{A} \geq \frac{a+c}{3} .\end{cases}\right.
$$

The equilibrium production levels are

$$
q_{A}^{a}=q_{B}^{a}=Q^{a}= \begin{cases}\frac{a-d_{A}-c}{4 b}, & \text { if } c<d_{A}<\frac{a+c}{3}, \\ \frac{a-2 c}{6 b}, & \text { if } d_{A} \geq \frac{a+c}{3}\end{cases}
$$

The equilibrium profits, excluding the fixed compensation $x$, are given as

$$
\begin{aligned}
& \pi_{D}^{a}= \begin{cases}\frac{\left(a-d_{A}-c\right)^{2}}{16 b} & \text { if } c<d_{A}<\frac{a+c}{3}, \\
\frac{(a-2 c)^{2}}{36 b} & \text { if } d_{A} \geq \frac{a+c}{3},\end{cases} \\
& \pi_{I A}^{a}= \begin{cases}\frac{\left(d_{A}-c\right)\left(a-d_{A}-c\right)}{4 b} & \text { if } c<d_{A}<\frac{a+c}{3}, \\
\frac{(a-2 c)^{2}}{18 b}, & \text { if } d_{A} \geq \frac{a+c}{3},\end{cases} \\
& \pi_{I B}^{a}= \begin{cases}\frac{\left(a-d_{A}-c\right)^{2}}{8 b} & \text { if } c<d_{A}<\frac{a+c}{3}, \\
\frac{(a-2 c)^{2}}{18 b} & \text { if } d_{A} \geq \frac{a+c}{3} .\end{cases}
\end{aligned}
$$

Second, we consider the case where $U_{I B}$ 's exclusive offer is rejected in Stage 1 . As in the first case, the existence of $U_{E A}$ acts as a constraint on the pricing of $U_{I A}$. The equilibrium 
supplier of input $B$ is $U_{E B}$ and its price is $w_{B}^{r}=c$. The maximization problem of $D$ in Stage 4 is given as (8). The output of the final product supplied by $D$ and the demand for each input are given as (9). The maximization problem of $U_{I A}$ in Stage 3 is given as

$$
\max _{w_{A}}\left(w_{A}-c\right) \frac{a-w_{A}-c}{2 b}, \text { s.t. } w_{A} \leq d_{A} .
$$

This maximization problem leads to

$$
w_{A}^{r}= \begin{cases}d_{A} & \text { if } c<d_{A}<\frac{a}{2}, \\ \frac{a}{2} & \text { if } d_{A} \geq \frac{a}{2} .\end{cases}
$$

The equilibrium production levels are

$$
q_{A}^{r}=q_{B}^{r}=Q^{r}= \begin{cases}\frac{a-d_{A}-c}{2 b}, & \text { if } c<d_{A}<\frac{a}{2} \\ \frac{a-2 c}{4 b}, & \text { if } d_{A} \geq \frac{a}{2} .\end{cases}
$$

The equilibrium profits are given as

$$
\begin{aligned}
& \pi_{D}^{r}= \begin{cases}\frac{\left(a-d_{A}-c\right)^{2}}{4 b}, & \text { if } c<d_{A}<\frac{a}{2} \\
\frac{(a-2 c)^{2}}{16 b}, & \text { if } d_{A} \geq \frac{a}{2},\end{cases} \\
& \pi_{I A}^{r}= \begin{cases}\frac{\left(d_{A}-c\right)\left(a-d_{A}-c\right)}{2 b}, & \text { if } c<d_{A}<\frac{a}{2} \\
\frac{(a-2 c)^{2}}{8 b}, & \text { if } d_{A} \geq \frac{a}{2},\end{cases} \\
& \pi_{I B}^{r}=0 .
\end{aligned}
$$

From now on, we explore the existence of exclusion. By using above results, we have

$$
\begin{aligned}
& \pi_{I B}^{a}+\pi_{D}^{a}-\left(\pi_{I B}^{r}+\pi_{D}^{r}\right) \\
&= \begin{cases}-\frac{\left(a-d_{A}-c\right)^{2}}{16 b} & \text { if } c<d_{A}<\frac{a+c}{3}, \\
\frac{\sqrt{3}\left\{d_{A}-((a-c)-(a-2 c) / \sqrt{3})\right\}\left\{(a-2 c)+\sqrt{3}\left(a-d_{A}-c\right)\right\}}{12 b} & \text { if } \frac{a+c}{3} \leq d_{A}<\frac{a}{2}, \\
\frac{(a-2 c)^{2}}{48 b} & \text { if } d_{A} \geq \frac{a}{2} .\end{cases}
\end{aligned}
$$


It is easy to see that condition (5) holds if and only if $d_{A} \geq \bar{d}_{A}$.

Q.E.D.

\section{References}

Abito, J.M., and Wright, J., 2008. Exclusive Dealing with Imperfect Downstream Competition. International Journal of Industrial Organization 26(1), 227-246.

Aghion, P., and Bolton, P., 1987. Contracts as a Barrier to Entry. American Economic Review 77(3), 388-401.

Arya, A., and Mittendorf, B., 2007. Interacting Supply Chain Distortions: The Pricing of Internal Transfers and External Procurement. Accounting Review 82(3), 551-580.

Argenton, C., 2010. Exclusive Quality. Journal of Industrial Economics 58(3), 690-716.

Argenton, C., and Willems, B., 2012. Exclusivity Contracts, Insurance and Financial Market Foreclosure. Journal of Industrial Economics 60(4), 609-630.

Asker, J., and Bar-Isaac, H., 2014. Raising Retailers' Profits: On Vertical Practices and the Exclusion of Rivals. American Economic Review 104(2), 672-686.

Bernheim, B.D., and Whinston, M.D., 1998. Exclusive Dealing. Journal of Political Economy 106(1), 64-103.

Besanko, D.P, and Perry, M.K., 1993. Equilibrium Incentives for Exclusive Dealing in a Differentiating Products Oligopoly. RAND Journal of Economics 24(4), 646-668.

Bork, R.H., 1978. The Antitrust Paradox: A Policy at War with Itself. New York: Basic Books.

Calzolari, G., and Denicolò, V., 2013. Competition with Exclusive Contracts and Market-Share Discounts. American Economic Review 103(6), 2384-2411. 
Chen, Y., and Sappington, D.E.M., 2011. Exclusive Contracts, Innovation, and Welfare. American Economic Journal: Microeconomics 3(2), 194-220.

de Fontenay, C.C., Gans, J.S., and Groves, V., 2010. Exclusivity, Competition, and the Irrelevance of Internal Investment. International Journal of Industrial Organization 28(4), $336-340$.

DeGraba, P., 2013. Naked Exclusion by an Input Supplier: Exclusive Contracting Loyalty Discounts. International Journal of Industrial Organization 31(5), 516-526.

de Meza, D., and Selvaggi, M., 2007. Exclusive Contracts Foster Relationship-Specific Investment. RAND Journal of Economics 38(1), 85-97.

Fumagalli, C., and Motta, M., 2006. Exclusive Dealing and Entry, When Buyers Compete. American Economic Review 96(3), 785-795.

Fumagalli, C., Motta, M., and Rønde, T., 2012. Exclusive Dealing: Investment Promotion may Facilitate Inefficient Foreclosure. Journal of Industrial Economics 60(4), 599-608.

Gans, J.S., 2013. Intel and Blocking Practices. The Antitrust Revolution: Economics, Competition, and Policy. 6th Edition, edited by J. Kwoka and L. White, New York: Oxford Univ Press.

Gratz, L. and Reisinger, M., 2013. On the Competition Enhancing Effects of Exclusive Dealing Contracts. International Journal of Industrial Organization 31(5), 429-437.

Hart, O., and Tirole, J., 1990. Vertical Integration and Market Foreclosure. Brooking Papers on Economic Activity: Microeconomics, 205-286.

Kitamura, H., 2010. Exclusionary Vertical Contracts with Multiple Entrants. International Journal of Industrial Organization 28(3), 213-219.

Kitamura, H., 2011. Exclusive Contracts under Financial Constraints. B.E. Journal of Economic Analysis $\mathcal{E}$ Policy 11, Article 57. 
Kitamura, H., Sato, M., and Arai, K., 2014. Exclusive Contracts when the Incumbent can Establish a Direct Retailer. Journal of Economics 112(1), 47-60.

Laussel, D., 2008. Buying Back Subcontractors: The Strategic Limit of Backward Integration. Journal of Economics $\mathcal{G}$ Management Strategy 17(4), 895-911.

Laussel, D., and Long, N.V., 2012. Vertical Disintegration: A Dynamic Markovian Approach. Journal of Economics $\mathcal{E}$ Management Strategy 21(3), 745-771.

Marvel, H.P., 1982. Exclusive Dealing. Journal of Law and Economics 25(1), 1-25.

Mathewson, G.F., and Winter, R.A., 1984. An Economic Theory of Vertical Restraints. RAND Journal of Economics 15(1), 27-38.

Matsumura, T., 2003. Consumer-Benefiting Exclusive Territories. Canadian Journal of Economics 36(4), 1007-1025.

Matsushima, N., and Mizuno, T., 2012. Equilibrium Vertical Integration with Complementary Input Markets. B.E. Journal of Economic Analysis E Policy 12, Article 26.

Matsushima, N., and Mizuno, T., 2013. Vertical Separation as a Defense against Strong Suppliers. European Journal of Operational Research 228(1), 208-216.

McAfee, R.P., and Schwartz, M., 1994. Opportunism in Multilateral Vertical Contracting: Nondiscrimination, Exclusivity, and Uniformity. American Economic Review 84(1), 210-230.

Motta, M., 2004. Competition Policy. Theory and Practice. Cambridge: Cambridge University Press.

Nagaoka, S., and Goto, A., 1997. Vertical Restraints and Market Access. Emprica 24(1-2), $21-36$.

O’Brien, D., and Shaffer, G., 1992. Vertical Control with Bilateral Contracts. RAND Journal of Economics 23(3), 299-308. 
Posner, R.A., 1976. Antitrust Law: An Economic Perspective. Chicago: University of Chicago Press.

Rasmusen, E.B., Ramseyer, J.M., and Wiley Jr., J.S., 1991. Naked Exclusion. American Economic Review 81(5), 1137-1145.

Reisinger, M., and Tarantino, E., 2013. Vertical Integration with Complementary Inputs. mimeo.

Rey, P., and Stiglitz, J., 1995. The Role of Exclusive Territories in Producers' Competition. RAND Journal of Economics 26(3), 431-451.

Rey, P., and Tirole, J., 1986. The Logic of Vertical Restraints. American Economic Review 76(5), 921-939.

Rey, P., and Tirole, J., 2007. A Primer on Foreclosure. Handbook of Industrial Organization, Volume 3 Ch. 33, edited by M. Armstrong and R.H. Porter, 2145-2220, Amsterdam: North Holland.

Rey, P., and Vergé, T., 2004. Bilateral Control with Vertical Contracts. RAND Journal of Economics 35(4), 728-746.

Rey, P., and Vergé, T., 2008. Economics of Vertical Restraints. Handbook of Antitrust Economics Ch. 9, edited by P. Buccirossi, 353-390, Boston: MIT Press.

Rey, P., and Vergé, T., 2010. Resale Price Maintenance and Interlocking Relationships. Journal of Industrial Economics 58(4), 928-961.

Segal, I.R., and Whinston, M.D., 2000a. Naked Exclusion: Comment. American Economic Review 90(1), 296-309.

Segal, I.R., and Whinston, M.D., 2000b. Exclusive Contracts and Protection of Investments. RAND Journal of Economics 31(4), 603-633. 
Simpson, J., and Wickelgren, A.L., 2007. Naked Exclusion, Efficient Breach, and Downstream Competition. American Economic Review 97(4), 1305-1320.

Whinston, M.D., 2006. Lectures on Antitrust Economics. Cambridge: MIT Press.

Wright, J., 2008. Naked Exclusion and the Anticompetitive Accommodation of Entry. Economics Letters 98(1), 107-112.

Wright, J., 2009. Exclusive Dealing and Entry, when Buyers Compete: Comment. American Economic Review 99(3), 1070-1081.

Yong, J.S., 1999. Exclusionary Vertical Contracts and Product Market Competition. Journal of Business 72(3), 385-406. 


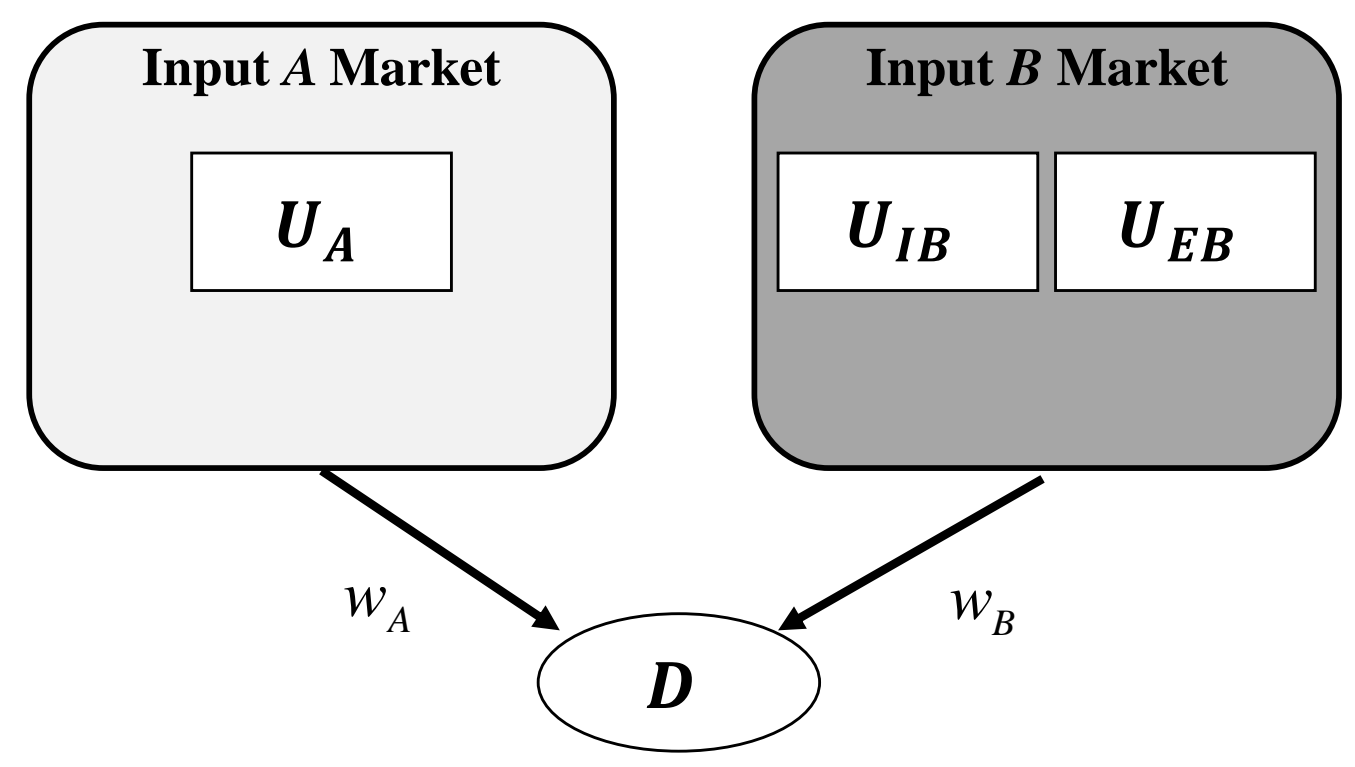

Figure 1: Market Structures

\begin{tabular}{lcll}
\multicolumn{1}{c}{ Stage 1 } & Stage 2 & Stage 3 & Stage 4 \\
\hline $\begin{array}{l}U_{I B} \text { makes an } \\
\text { exclusive offer. } \\
D \text { decides. }\end{array}$ & $\begin{array}{c}U_{E B} \text { makes } \\
\text { entry decision. }\end{array}$ & $\begin{array}{l}\text { Active suppliers } \\
\text { make input price } \\
\text { offers. }\end{array}$ & $\begin{array}{l}D \text { orders inputs } A \text { and } B \\
\text { and produces final products. }\end{array}$ \\
& &
\end{tabular}

Figure 2: Timeline 